\title{
openheart Need for expertise in mitral valve regurgitation
}

\author{
Erwan Donal, ${ }^{\oplus 1}$ Elena Galli, ${ }^{1}$ Thierry Letourneau ${ }^{2}$
}

To cite: Donal E, Galli E, Letourneau T. Need for expertise in mitral valve regurgitation. Open Heart 2019;6:e001039. doi:10.1136/ openhrt-2019-001039

Accepted 14 April 2019

Check for updates

\section{(c) Author(s) (or their} employer(s)) 2019. Re-use permitted under CC BY-NC. No commercial re-use. See rights and permissions. Published by BMJ.

${ }^{1}$ Department of Cardiovascular Diseases, Pontchaillou University Hospital \& LTSI INSERM1099, Université Rennes-1, Rennes, , France

${ }^{2}$ Institut du Thorax, Inserm, CNRS, Université de Nantes, $\mathrm{CHU}$ de Nantes, , France

Correspondence to Dr Erwan Donal, CHU Rennes, Rennes, Bretagne, France; erwan.donal@chu-rennes.fr
The mitral annulus is a three-dimensional, saddle-shaped structure exhibiting dynamic conformational changes during the cardiac cycle. ${ }^{1}$ The normal annulus contracts and increases in saddle-shaped non-planarity during systole. ${ }^{23}$ Such annular dynamics are important for the balanced distribution of the mechanical stresses imposed by the left ventricle $(\mathrm{LV})$ on the mitral valve apparatus. ${ }^{45}$

Mitral annular disjunction (MAD) is an anatomic abnormality of the mitral annulus described as a wide separation between the atrium-mitral valve junction and the $\mathrm{LV}$ attachment that is appreciable on both gross and histological examination. During reparative surgery for mitral valve prolapse (MVP), surgical evaluation can detect MAD as a superior displacement or atrialisation of the posterior leaflet base. Although MAD is found in a large proportion of patients with myxomatous MVP, ${ }^{6}$ it has also been described as an anatomic variation of mitral annulus morphology. MAD leads to paradoxical annular enlargement and flattening during systole, increasing leaflets and chordae stress, which may accelerate the degenerative process of mitral valve apparatus. It has been suggested that the mechanical traction of the papillary muscles and the posterolateral LV wall stretch can be arrhythmogenic. In addition, MAD elicits a sort of decoupling between annular and ventricular functions, ${ }^{67}$ which can increases LV wall stress, and ultimately leads to myocardial fibrosis and LV dysfunction (figure 1). However, such abnormal annular dynamics occurs generally despite relatively normal LV systolic function assessed by ejection fraction and often in the absence of severe mitral regurgitation.

Recent but consistent publications incriminated MAD as a possible aetiology of sudden cardiac death (SD), especially but not only, in patients with myxomatous MVP. In addition to $\mathrm{MAD}$, the classical pattern of $\mathrm{SD}$ in this setting associate bileaflet MVP in a young woman with biphasic or inverted T-waves in the inferior leads, and complex premature ventricular contractions (not related to exercise) on the 24 hours ECG recording. As MAD is a quite frequent finding by echocardiography or cardiac MRI, it is of paramount importance to distinguish MAD at risk for LV ventricular arrhythmias ${ }^{8}$ from MAD without increased risk. The work published in Open Heart, ${ }^{5}{ }^{6}$ based on both cardiac MRI and fibrosis biomarkers, provides new insights into the stratification of ventricular arrhythmia risk in MAD.

Cardiac MRI has been used not only for $\mathrm{LV}$ volumes and ejection fraction (EF) evaluation but also for MV apparatus assessment, MAD measurement and myocardial fibrosis evaluation by late gadolinium enhancement (LGE) analysis. Papillary muscles or basal posterolateral wall fibrosis was described in association with MAD, MVP and SD. In addition, local or diffuse LV myocardial fibrosis study is an important issue for predicting LV dysfunction when regurgitation is severe. ${ }^{69}$ In addition to cardiac MRI, authors provided some evidence in favour of the use of fibrosis biomarkers measured on blood samples. ${ }^{10}$ Indeed, the manuscript published in the current issue of Open Heart suggests that soluble suppression of tumorigenicity 2 (sST2) could be combined to imaging data for best predicting the risk of arrhythmogenic events in patients with MAD. sST2 is an interleukin 1 receptor family member secreted by cardiac cells in circumstances of biomechanical stress that can promote myocardial fibrosis. In the present work, sST2 was enhanced in patients with MAD and ventricular arrhythmias $(\mathrm{p}=0.01)$ and improved the differentiation of patients with and without ventricular arrhythmia in conjunction with LV, EF and papillary muscles LGE. ${ }^{11}$

Although further studies are needed in a larger population to confirm these findings, the present study provides new insights and suggests that cardiac MR and biomarkers of fibrosis might be used in combination for improving the risk stratification of severe ventricular arrhythmias in patients with MAD. 


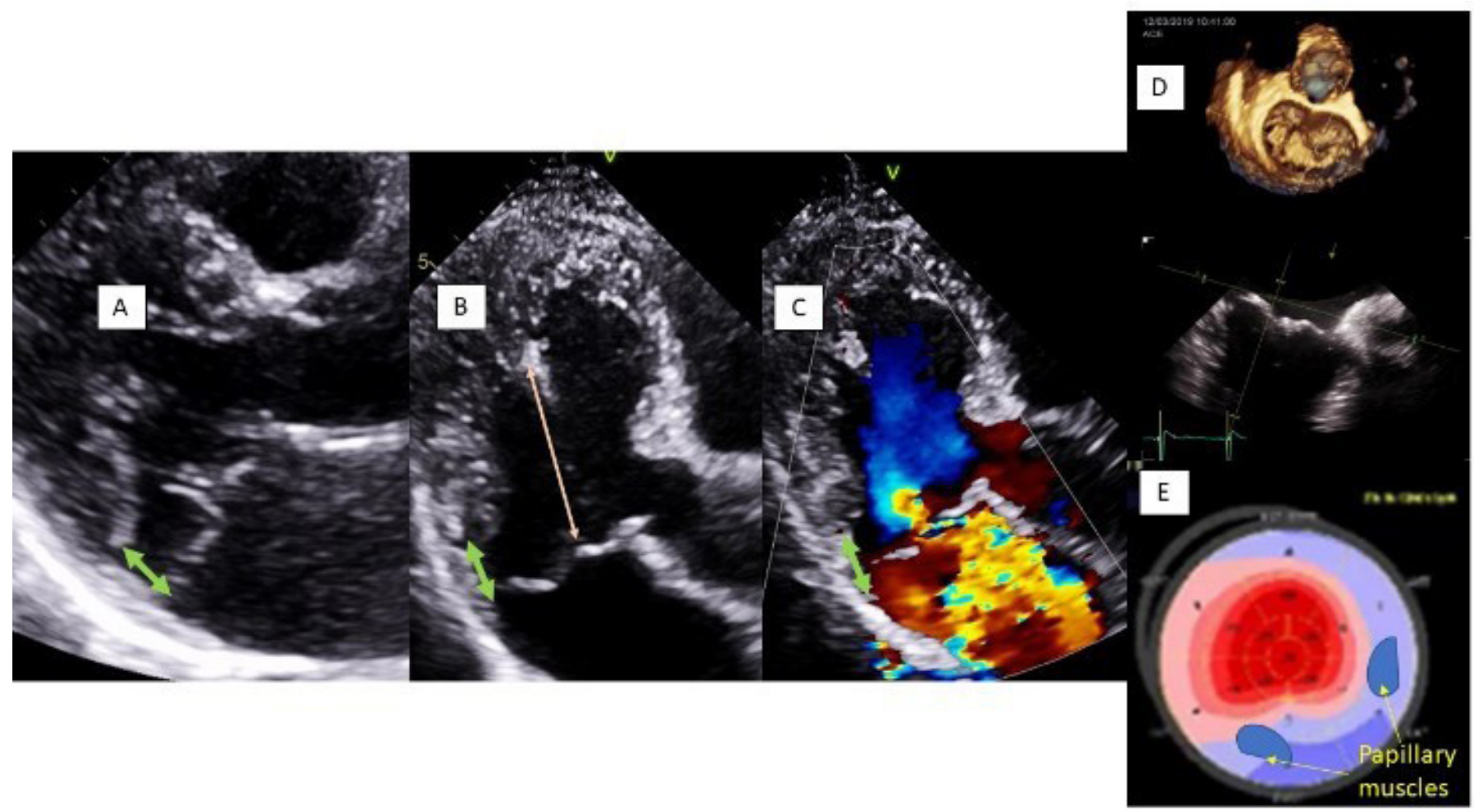

Figure 1 Example of a young woman with a bileaflet prolapse and a mitral annular disjunction (MAD). Longitudinal strain demonstrates the impact of MAD on left ventricular function. (A-C) MAD (double green arrow) in parasternal and apical long axis views. There is an atrialisation of a part of the left ventricle in regard of the posterior leaflet insertion. The sudden and excessive displacement of leaflets toward the left atrium in systole elicits an abnormal tension and stretch of chordae and papillary muscles. Not only the secondary chordae but also the chordae that are directly attached to the basal segments of the left ventricle. (D) In 3D-echo, the posterior leaflet prolapses totally in the left atrium in systole. The prolapse is less marked for the anterior leaflet in this example. (E) Mitral annulus disjunction can induce abnormal longitudinal deformation of left ventricular basal segments, associated with cardiac MRI to inferolateral basal myocardial wall fibrosis. 3D, three-dimensional.

Contributors All the co-authors were involved in the writing of the manuscript.

Funding This research received no specific grant from any funding agency in the public, commercial or not-for-profit sectors.

Competing interests None declared.

Provenance and peer review Commissioned; internally peer reviewed.

Open access This is an open access article distributed in accordance with the Creative Commons Attribution Non Commercial (CC BY-NC 4.0) license, which permits others to distribute, remix, adapt, build upon this work non-commercially, and license their derivative works on different terms, provided the original work is properly cited, appropriate credit is given, any changes made indicated, and the use is non-commercial. See: http://creativecommons.org/licenses/by-nc/4.0/.

\section{REFERENCES}

1. Chen T-E, Ong K, Suri RM, et al. Three-dimensional echocardiographic assessment of mitral annular physiology in patients with degenerative mitral valve regurgitation undergoing surgical repair: comparison between early- and late-stage severe mitral regurgitation. J Am Soc Echocardiogr 2018;31:1178-89.

2. Enriquez-Sarano M, Avierinos J-F, Messika-Zeitoun D, et al. Quantitative determinants of the outcome of asymptomatic mitral regurgitation. N Engl J Med 2005;352:875-83.
3. Hourdain J, Clavel MA, Deharo J-C, et al. Common phenotype in patients with mitral valve prolapse who experienced sudden cardiac death. Circulation 2018;138:1067-9.

4. Basso C, Perazzolo Marra M, Rizzo S, et al. Arrhythmic mitral valve prolapse and sudden cardiac death. Circulation 2015;132:556-66.

5. Basso C, Perazzolo Marra M. Mitral annulus disjunction: Emerging role of myocardial mechanical stretch in Arrhythmogenesis. J Am Coll Cardiol 2018;72:1610-2.

6. Dejgaard LA, Skjølsvik ET, Lie Øyvind $\mathrm{H}$, et al. The mitral annulus disjunction arrhythmic syndrome. J Am Coll Cardiol 2018;72:1600-9.

7. Enriquez-Sarano M. Mitral Annular Disjunction: The Forgotten Component of Myxomatous Mitral Valve Disease. JACC Cardiovasc Imaging 2017;10:1434-6.

8. Han H-C, Ha FJ, Teh AW, et al. Mitral valve prolapse and sudden cardiac death: a systematic review. J Am Heart Assoc 2018;7:e010584.

9. Bui AH, Roujol S, Foppa M, et al. Diffuse myocardial fibrosis in patients with mitral valve prolapse and ventricular arrhythmia. Heart 2017;103:204-9.

10. Galeone A, Lessana A, Mascolo E, et al. Interleukin-1 receptorrelated protein ST2 and mitral valve repair outcome in patients with chronic degenerative mitral regurgitation. Thorac Cardiovasc Surg 2014;62:47-51.

11. Scheirlynck ES, Dejgaard LA, Skjolsvik E, et al. Increased levels of Sst2 in patients with mitral annulus disjunction and ventricular arrhythmias. Open Heart. In Press 2019. 